\title{
An arachnoid cyst you don't see every day
}

\begin{tabular}{|c|}
\hline $\begin{array}{l}\text { Ioan-Cristian Lupescu1, Ioana-Gabriela Lupescu²,3, Razvan Cerban, } \\
\text { Liliana Gheorghe }{ }^{3,4} \text {, Daniela Anghel }{ }^{1,3}\end{array}$ \\
\hline $\begin{array}{l}{ }^{1} \text { Neurology Department, Fundeni Clinical Institute, Bucharest, Romania } \\
{ }^{2} \text { Radiology and Imaging Department, Fundeni Clinical Institute, Bucharest, Romania } \\
\text { 3“Carol Davila“ University of Medicine and Pharmacy, Bucharest, Romania } \\
{ }^{4} \text { Gastroenterology Department, Fundeni Clinical Institute, Bucharest, Romania }\end{array}$ \\
\hline
\end{tabular}

\begin{abstract}
A 53 years-old male, diagnosed with ulcerative colitis and liver cirrhosis due to HCV infection, was hospitalized at the Gastroenterology Department for paraclinical workup, prior to inclusion on the liver transplantation waiting list. The patient was known with a gigantic arachnoid cyst and presented a transient ischemic attack one year prior, for which treatment with aspirin was initiated. Consequently, we performed a brain MRI examination, which disclosed a left-sided gigantic arachnoid cyst with mass effect, midline shift of $9 \mathrm{~mm}$ and subfalcine herniation. No focal neurologic deficits or signs of increased intracranial pressure were found on neurological examination. Following neurosurgical evaluation, the presence of the cyst was not deemed to be a contraindication for liver transplantation.
\end{abstract}

Keywords: arachnoid cyst, Galassi classification, middle cranial fossa

\author{
Abbreviations \\ CSF - cerebrospinal fluid \\ $\mathrm{CT}$ - computed tomography \\ DWI - diffusion weighted imaging \\ FLAIR - fluid attenuated inversion recovery \\ $\mathrm{HCV}$ - hepatitis $\mathrm{C}$ virus \\ IR - inversion recovery \\ MRI - magnetic resonance imaging
}

\section{INTRODUCTION}

Arachnoid cysts are CSF-filled lesions, usually congenital in nature [1], consisting of duplications or splitings of the arachnoid layer [2].

In approximately half of cases, they are found in the vicinity of the sylvian fissure [3], i.e. in the middle cranial fossa. However they have been described in many other locations, e.g. in the sellar or suprasellar regions (near the third ventricle), quadrigeminal cistern, near the midline of the brain (parasagittal) or interhemispheric, over the cerebral convexities, or in the posterior fossa [4,5].

Three mechanisms have been proposed to explain the progressive enlargement of arachnoid cysts over time: (a) secretion of fluid by ependymal cells, (b) accumulation of fluid through an osmotic mechanism, (c) trapping of fluid through a ball-valve mechanism [6].

\section{CASE PRESENTATION}

We present the case of a 53 years-old male with liver cirrhosis due to $\mathrm{HCV}$ infection, who came to the Gastroenterology Department for paraclinical workup prior to inclusion on the liver transplantation waiting list. The patient was also known with ulcerative colitis and a gigantic arachnoid cyst and presented a possible transient ischemic attack (left hand numbness and dysarthria of approximately 5 
seconds duration), for which treatment with aspirin was initiated.

Neurological examination was unrevealing, apart from post-traumatic left-sided amblyopia with nonparalytic strabismus (acquired during childhood).

However, we performed a brain MRI, which highlighted an extensive left-sided extra-axial accumulation of fluid, without diffusion restriction, without a well-defined capsule, measuring 15.5/5.6 centimeters in the axial plane and 10.5 centimeters in the cranio-caudal plane, with important mass effect, partial collapse of the left ventricle and midline shift of $9 \mathrm{~mm}$ with subfalcine hernation (see Figure 1). The lesion was classified as a type III Galassi arachnoid cyst. Subsequent neurosurgical evaluation established that it did not represent a contraindication for liver transplantation.

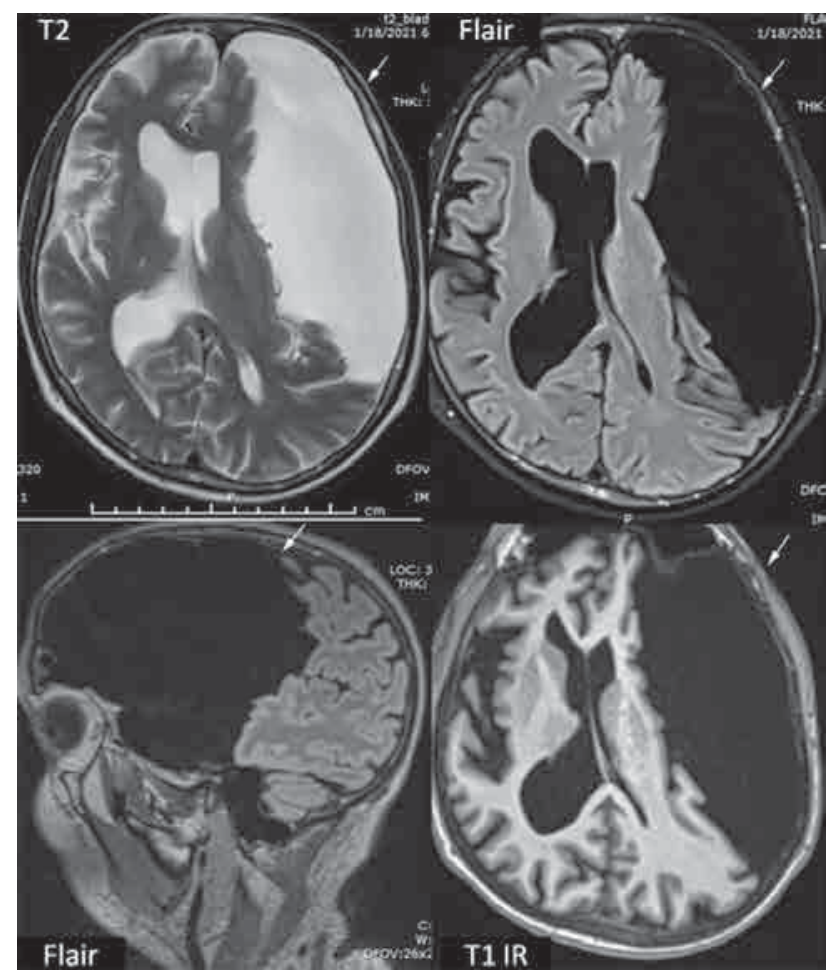

FIGURE 1. Left-sided extra-axial gigantic accumulation of fluid with CSF-signal on T2, FLAIR and T1 IR, determining mass effect, midline shift and subfalcine herniation

\section{DISCUSSIONS}

The imaging diagnosis of arachnoid cysts is pretty straightforward, since the fluid collection has the same density or intensity as the CSF (depending on whether CT or MRI is used), and doesn't enhance with any contrast administration. The main differential diagnosis is with epidermoid cysts, and this is best settled by MRI. The arachnoid cyst suppresses completely with FLAIR and shows no diffusion restriction on DWI, while the epidermoid cyst does the opposite, that is, it appears hyperintense on both FLAIR and DWI. Other diagnostic considerations are chronic subdural hematoma and subdural hygroma, (which are usually bilateral and crescent shaped) or cystic meningioma (which shows ring enhacement) $[3,7]$.

It should be noted that arachnoid cysts are common lesions, usually found incidentally during imaging procedures, and the vast majority of them are asymptomatic.

For example, Al-Holou et al analyzed retrospectively 48417 patients who underwent brain MRI and detected arachnoid cysts in 661 of them, accounting for a prevalence of $1.4 \%$. Of the 661 patients, only 35 were considered symptomatic $(\sim 5.3 \%)[8]$.

Arachnoid cysts can give rise to intracranial hypertension, and sometimes to focal neurological deficits [1]. Sellar and suprasellar cysts are more likely to become symptomatic, while those located in the middle cranial fossa are less likely [8]. In the pediatric patients, headache is the most frequently reported symptom [9].

Other complications include intracystic hemorrhage, or rupture of the cyst into the subdural space, leading to development of a subdural hygroma [10]. Intracystic hemorrhage can also rupture and give rise to subdural hematoma [11].

Arachnoid cysts of the middle cranial fossa (which are the most common) can be graded into three types. This classification was proposed by Galassi in 1982 and takes into account their dimensions and extent, as well as their communication with the subarachnoid space (see Table 1) [12].

TABLE 1. Galassi classification of middle cranial fossa arachnoid cysts

\begin{tabular}{|c|l|}
\hline Type & Characteristics \\
\hline I & $\begin{array}{l}\text { Small and limited to the anterior portion of the } \\
\text { middle cranial fossa } \\
\text { Free communication with the subarachnoid space. }\end{array}$ \\
\hline II & $\begin{array}{l}\text { Extend along the sylvian fissure and can displace } \\
\text { the temporal lobe } \\
\text { Slow communication with the subarachnoid space. }\end{array}$ \\
\hline III & $\begin{array}{l}\text { Large, fill the whole middle cranial fossa; there is } \\
\text { displacement of multiple lobes and often there is } \\
\text { midline shift. } \\
\text { Little communication with the subarachnoid space. }\end{array}$ \\
\hline
\end{tabular}


Usually, if the cysts are asymptomatic, they should be left alone and monitored [1]. Otherwise, different neurosurgical approaches exist for symptomatic cysts, the most common being microsurgical fenestration through craniotomy, endoscopic fenestration and cystoperitoneal shunting [4]. Endoscopic techniques have been used successfully in this regard, with resolution or improvement of symptoms in the majority of patients, and no peri-operative mortality or significant morbidity [13]. Other authors however, have noted a high proportion of relapses after endoscopic fenestration and achieved better results with microsurgical fenestration [14]. The choice of neurosurgical treatment is also influenced by the location of

Conflict of interest: none declared

Financial support: none declared

\section{REFERENCES}

1. Allan HR, Martin AS, Joshua PK, Sashank P. Intracranial Neoplasms and Paraneoplastic Disorders. In: Allan HR, Martin AS, Joshua PK, Sashank P. Adams and Victor's Principles of Neurology - 11th Edition. McGraw-Hill Educational, 2019:694.

2. Westermaier T, Schweitzer T, Ernestus RI. Arachnoid cysts. Adv Exp Med Biol. 2012;724:37-50.

3. Kress B. Cysts. In: Sartor K, Haehnel S, Kress B. Brain Imaging (Direct Diagnosis in Radiology). Thieme, 2008:181-183.

4. Mustansir F, Bashir S, Darbar A. Management of Arachnoid Cysts: A Comprehensive Review. Cureus. 2018;10(4):e2458.

5. Srinivasan US, Lawrence R. Posterior fossa arachnoid cysts in adults: Surgical strategy: Case series. Asian J Neurosurg. 2015;10(1):47.

6. Dyck P, Gruskin P. Supratentorial arachnoid cysts in adults. A discussion of two cases from a pathophysiologic and surgical perspective. Arch Neurol. 1977 May;34(5):276-279.

7. Osborn AG. Arachnoid Cyst. In Osborn A.G. et al. Diagnostic Imaging: Brain, First Edition. Amyrsis, 2004: I-7-4.

8. Al-Holou WN, Terman S, Kilburg C, et al. Prevalence and natural history of arachnoid cysts in adults. J Neurosurg. 2013; 118(2):222-231.

9. Mazurkiewicz-Bełdzińska M, Dilling-Ostrowska E. Presentation of intracranial arachnoid cysts in children: correlation between arachnoid cysts. In one study, the best results were obtained by using fenestration with cystoperitoneal shunting for supratentorial cysts, endoscopic fenestration for midline cysts and cystoperitoneal shunting for infratentorial cysts [15].

\section{CONCLUSIONS}

Arachnoid cysts are usually asymptomatic lesions, found incidentally on imaging procedures. However, they can grow to enormous size, at times causing mass effect and compressing nearby structures. Periodic neurological and imaging assessment is therefore recommended.

localization and clinical symptoms. Med Sci Monit. 2002; 8(6):CR462-5.

10. Jafrani R, Raskin JS, Kaufman A, Lam S. Intracranial arachnoid cysts: Pediatric neurosurgery update. Surg Neurol Int. 2019;10:15.

11. Hall A, White MAJ, Myles L. Spontaneous subdural haemorrhage from an arachnoid cyst: a case report and literature review. Br J Neurosurg. 2017;31(5):607-610.

12. Galassi E, Tognetti F, Gaist G, et al. CT scan and metrizamide CT cisternography in arachnoid cysts of the middle cranial fossa: classification and pathophysiological aspects. Surg Neurol. 1982;17(5):363-369.

13. Karabatsou K, Hayhurst C, Buxton N, et al. Endoscopic management of arachnoid cysts: an advancing technique. J Neurosurg. 2007;106(6 Suppl):455-462.

14. Holst AV, Danielsen PL, Juhler M. Treatment options for intracranial arachnoid cysts: a retrospective study of 69 patients. Acta Neurochir Suppl. 2012;114:267-270.

15. Ahn JY, Chio JU, Yoon SH, et al. Treatment and Outcome of Intracranial Arachnoid Cysts. J Korean Neurosurg Soc. 1994;23(2):194-203. 